Review

\title{
Supramolecular Chirality in Dynamic Coordination Chemistry
}

\section{Hiroyuki Miyake}

Department of Chemistry, Graduate School of Science, Osaka City University, Sugimoto, Sumiyoshi-ku, Osaka 558-8585, Japan; E-Mail: miyake@ @ci.osaka-cu.ac.jp;

Tel./Fax: +81-6-6605-3124

External Editor: Victor Borovkov

Received: 26 September 2014; in revised form: 16 October 2014 / Accepted: 17 October 2014 /

Published: 24 October 2014

\begin{abstract}
Labile metal complexes have a useful coordination bond; which is weaker than a covalent $\mathrm{C}-\mathrm{C}$ bond and is reversibly and dynamically formed and dissociated. Such labile metal complexes also can be used to construct chiral shapes and offer dynamic conversion of chiral molecular shapes in response to external stimuli. This review provides recent examples of chirality induction and describes the dynamic conversion systems produced by chiral metal complexes including labile metal centers, most of which respond to external stimuli by exhibiting sophisticated conversion phenomena.
\end{abstract}

Keywords: supramolecular chirality; supramolecular chemistry; chirality; metal complex; coordination chemistry; coordination bond; conversion

\section{Introduction}

Supramolecular chirality is found in biological systems and plays an essential role in the transfer of biological information in living systems [1-4]. The classic example of the $\mathrm{F}_{1}$ motor in ATP synthase shows that supramolecular chirality can regulate the rotational direction of protein motors to maintain homeostasis [5,6]. Helicity switching between a right-handed B-DNA helix and a left-handed Z-DNA may be involved in regulating gene expression and in DNA processing events [6,7]. Polyproline adopts two helical structures, a right-handed type I helical structure and a left-handed type II helical structure, which are interconverted through a change in media polarity [8] and other external stimuli [9,10]. The cis-trans conversion of peptidyl-prolyl bonds can be catalyzed by prolyl isomerase to change the entire protein structure and to determine the rate of protein folding $[11,12]$. In these examples, noncovalent interactions play an important role in determining the helical structure. Although some artificial systems, 
such as small organic molecules [13-19], polymers [20-23], metamaterials [24], and assemblies [25-28], have been developed for chirality induction and switching in response to external stimuli, more sophisticated systems are required to mimic natural systems.

Metal complexes have features desirable for supramolecular chirality, including chirality induction and switching through their dynamic coordination bonds. Metalloporphyrins and coordinatively unsaturated lanthanide complexes are typical examples for chirality induction exhibiting chirality sensing of external substrates via dynamic coordination [29-31]. Furthermore, the metal complexes can function as chiral building units for a variety of molecular geometries including linear, triangular, tetrahedral, octahedral, and higher polyhedral structures [32-35], some of which are easily converted to each other in response to environmental conditions. Their stereoisomers often have similar free energy, which results in labile metal complexes being generated as a racemate and/or coexisting in solution (Figure 1). Designing labile metal complexes with isomers having a free energy difference great enough to produce one isomer could provide a sophisticated structural conversion system through switching of this energy balance. Dynamic attachment and detachment features of coordination bonds can be applied to construct molecular machines. Sauvage et al. developed copper-mediated dynamic catenanes and rotaxanes [36,37]. The $\mathrm{Cu}(\mathrm{II})$ center prefers 5- or 6-coordination and possesses rapid ligand exchange character $\left(5.7 \times 10^{9} \mathrm{~s}^{-1}\right.$ for water exchange rate $k_{1}$ of $\left[\mathrm{Cu}\left(\mathrm{H}_{2} \mathrm{O}\right)_{5}\right]^{2+}$ at $\left.298 \mathrm{~K}\right)$ [38], and the $\mathrm{Cu}(\mathrm{I})$ center prefers 4 -coordination geometry. Thus, $\mathrm{Cu}(\mathrm{II}) / \mathrm{Cu}(\mathrm{I})$ redox switching triggered ligand rearrangement between 5-coordination and 4-coordination, resulting in dynamic molecular machines.

Figure 1. Representative enantiomeric pairs based on coordination geometries of metal complexes: (a) square planar; (b) tetrahedral; (c) trigonal pyramid; (d) octahedral with tris(bidentates); (e) octahedral with linear tetradentate; (f) square antiprism with tetra(bidentates); (g) square antiprism with tetra-armed cyclen.

(a)

(b)

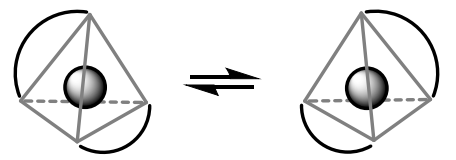

(c)

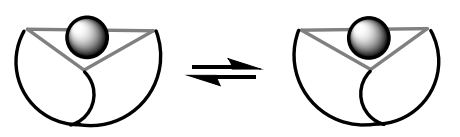

(d)

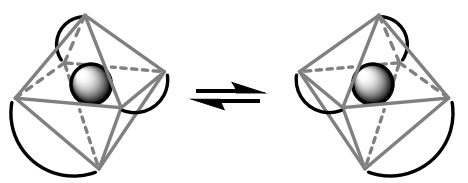

(e)

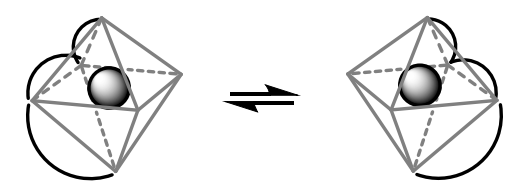

(f)

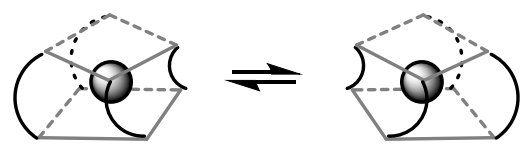

(g)

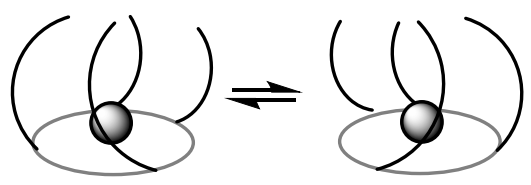

\section{Supramolecular Chirality from Helicates to Foldamers}

Metallo-helicates are typical mimics of the DNA helical structures and so have been investigated thoroughly. Most helicates have been prepared from $\mathrm{Cu}(\mathrm{I})$ and $\mathrm{Ag}(\mathrm{I})$ metal centers and polybidentate ligands, in which the metal centers have tetrahedral geometry as demonstrated initially by Lehn et al. [39]. Several types of helicates, such as duplexes, triplexes, and their chiral derivatives 
have been developed [40-42]. Recently, unique chiral helicates have been reported. Furusho and Yashima designed double-stranded metal helicate polymers, in which amidinium-carboxylate salt bridges and inert $\mathrm{Pt}(\mathrm{II})$-acetylide coordination cooperated to provide a complementary one-handed duplex (Figure 2) [43]. A characteristic induced CD signal was observed in the Pt(II)-acetylide complex region, indicating that the chirality of the phenylethyl groups on the amidinium unites was transferred to the $\mathrm{Pt}(\mathrm{II})$ center to produce the preferred one-handed helical structure in solution.

Figure 2. Double-stranded metal helicate polymer consisting of chiral amidine and an achiral carboxylic acid $(\mathrm{R}=$ octynyl).

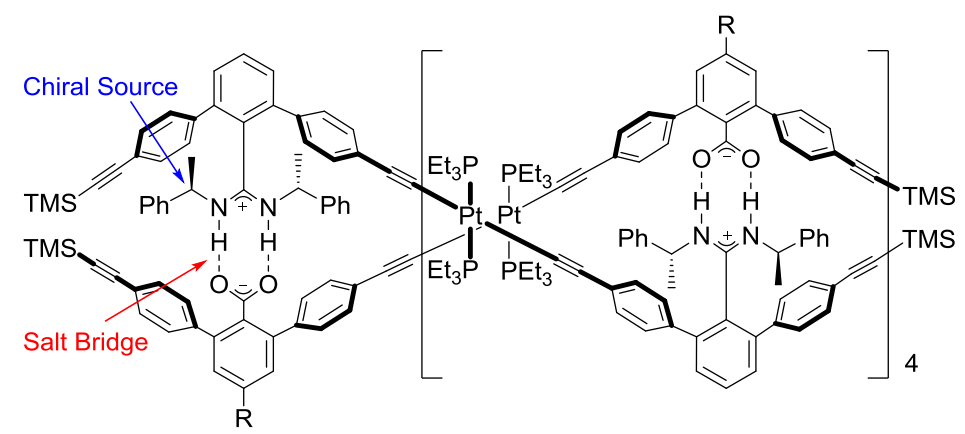

A new type of $\mathrm{Cu}(\mathrm{I})$ double-stranded helicate was also prepared from ketamine-bridged tris(bipyridine) ligands (Figure 3) [44]. The tetranuclear $\mathrm{Cu}(\mathrm{I})$ helicate prepared was a racemic mixture of right- and left-handed helical structures. Although the $\mathrm{Cu}(\mathrm{I})$ cation has a generally typical labile character [38], the racemate was successfully resolved to each enantiomer. The racemate was treated with chiral binaphthyl hydrogen phosphate anion and the diastereomeric salt obtained was treated further with $\mathrm{NH}_{4} \mathrm{PF}_{6}$ to obtain an optically pure enantiomer. During anion exchange, no racemization of the helicate was observed.

Figure 3. $\mathrm{Cu}(\mathrm{I})$ double-stranded helicate consisting of ketamine-bridged tris(bipyridine).

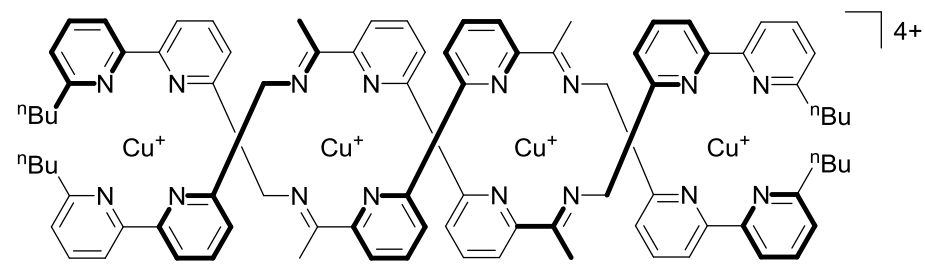

Fabbrizzi et al. prepared a dinuclear $\mathrm{Cu}(\mathrm{I})$ double-stranded helicate by condensation of $R, R-1,2$-cyclohexanediamine and 8-naphthylmethoxyquinoline-2-carbaldehyde, followed by complexation with $\left[\mathrm{Cu}\left(\mathrm{CH}_{3} \mathrm{CN}\right)_{4}\right]\left(\mathrm{ClO}_{4}\right)$ (Figure 4) [45]. The one-handed helicate obtained was stabilized by the presence of four interstrand $\pi-\pi$ interactions involving quinoline and naphthyloxymethylene moieties and showed a fully reversible one-electron oxidation despite the labile character of the $\mathrm{Cu}(\mathrm{I})$ centers.

Because these helicate systems contain Schiff base binding sites that are easily and rapidly produced by mixing a primary amine and aldehyde in situ, the preparation of these helicates is convenient and suitable for systematic studies for discovering novel functions [46,47]. 
Figure 4. $\mathrm{Cu}(\mathrm{I})$ double-stranded helicate stabilized by $\pi-\pi$ interactions.

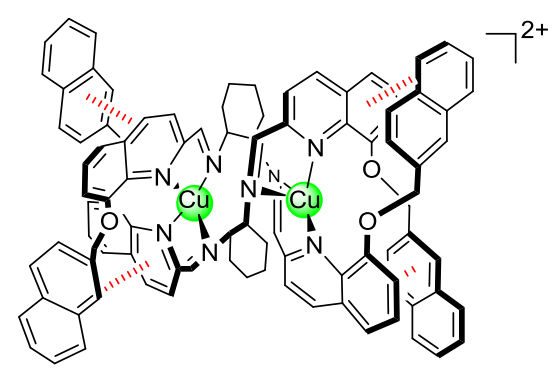

Metal complexes consisting of a $\mathrm{d}^{8}$ transition metal cation, such as $\mathrm{Ni}(\mathrm{II}), \mathrm{Pd}(\mathrm{II})$, and $\mathrm{Pt}(\mathrm{II})$ complexes, favor a square planar structure suitable for construction of highly ordered chain architectures, including helices and sheets. Among these $\mathrm{d}^{8}$ metal complexes, $\mathrm{Pd}(\mathrm{II})$ complexes often are used for the construction of molecular strands [48], coordination capsules [49], and spherical complexes [50]. Because the $\mathrm{Pd}(\mathrm{II})$ center has a hemi-labile coordination bond, dynamic molecular motion and ligand exchange phenomena have been investigated by ${ }^{1} \mathrm{H}$ NMR spectroscopy as well as other spectroscopic methods. Miyake recently synthesized a diastereomeric pair of left- and right-handed square planar $\mathrm{Pd}(\mathrm{II})$ complexes from a single chiral precursor $N_{S}, N_{S}-\mathrm{PdCl}_{2}$ complex (Figure 5) [51]. The precursor $N_{S}, N_{S}-\mathrm{PdCl}_{2}$ complex was prepared using the chiral ligand and $\mathrm{Na}_{2} \mathrm{PdCl}_{4}$, in which the $\mathrm{Pd}(\mathrm{II})$ center had a square planar structure coordinated by two tertiary amine nitrogens and two chloride anions. The precursor complex was converted quantitatively into the left-handed $N_{S}, N_{S}-\mathrm{PdCl}$ complex having a semi-contracted molecular shape upon addition of an equimolar amount of $\mathrm{Et}_{3} \mathrm{~N}$, during which one amide moiety was deprotonated to coordinate with the $\mathrm{Pd}(\mathrm{II})$ center. Both amine nitrogen-centered chiralities in these complexes possessed the $S$-configuration. The left-handed $N_{S}, N_{S}-\mathrm{PdCl}$ complex was rapidly inverted to the $R$-configuration to form the $N_{R}, N_{R}-\mathrm{PdCl}$ complex as the thermodynamic product. The half-life of the inversion was $1.5 \mathrm{~min}$ at $100{ }^{\circ} \mathrm{C}$. Interestingly, microwave irradiation at $120{ }^{\circ} \mathrm{C}$ directly converted the precursor $N_{S}, N_{S}-\mathrm{PdCl}_{2}$ complex to the right-handed $N_{R}, N_{R}-\mathrm{PdCl}$ complex. Since the $\mathrm{Pd}(\mathrm{II})$ center has a hemi-labile character, the $N_{S}, N_{S}-\mathrm{PdCl}$ complex could be trapped as a kinetic product and helicity inversion occurred rapidly under thermal condition and microwave irradiation.

Figure 5. Synthesis and helicity inversion of diastereomeric $\mathrm{Pd}(\mathrm{II})$ complexes. Reproduced by permission of The Royal Society of Chemistry [48].
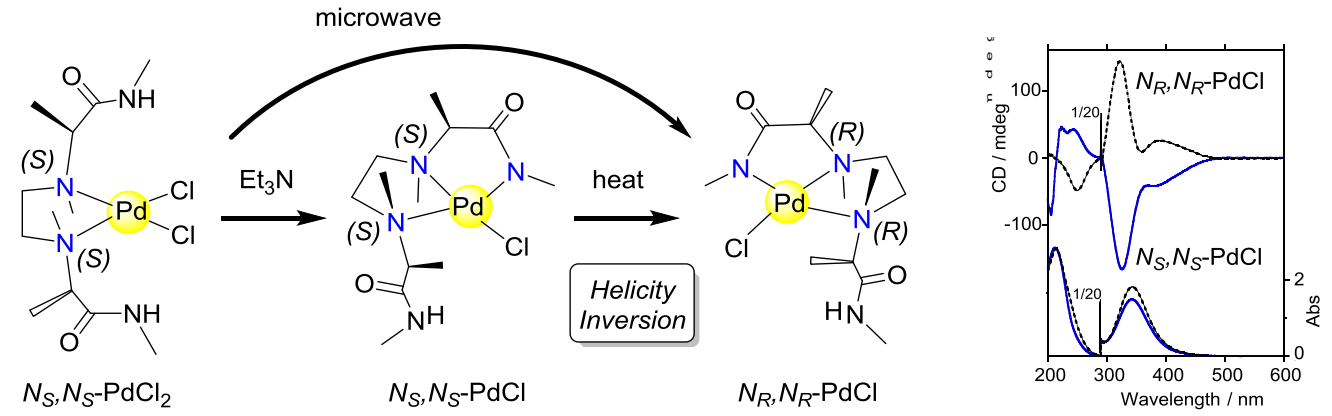

Attaching chiral amine moieties at the formyl group of the ligand conveniently and effectively induced chiral Schiff base ligands for metal complexation that can provide dynamic covalent bonds and is a promising methodology for developing supramolecular chirality chemistry in combination with 
metal complexes. Setsune developed single helicates of $\mathrm{Pd}(\mathrm{II})_{2}$ hexapyrroles (Figure 6) [52]. The $\mathrm{Pd}(\mathrm{II})_{2}$ hexapyrolle with terminal formyl groups favored a closed form, in which helicity underwent rapid interchange between two enantiomers at room temperature. Introduction of $(R)-(-)-1$-cyclohexylethylamine to the two terminal formyl groups significantly slowed the conformational change rate and induced helical handedness as high as $85 \%$ diastereoselectivity. One-electron oxidation of the $\mathrm{Pd}(\mathrm{II})_{2}$ complex changed the chiroptical property by shifting the CD spectra at $699 \mathrm{~nm}$ to $741 \mathrm{~nm}$ with induction of an intense ESR signal at $\mathrm{g}=2.001$ due to formation of a $\pi$ cation radical delocalized over the 2,2'-bisdipyrrin chromophore.

Figure 6. Helicity induction by Schiff base formation between a chiral amine and $\mathrm{Pd}(\mathrm{II})_{2}$ hexapyrroles.
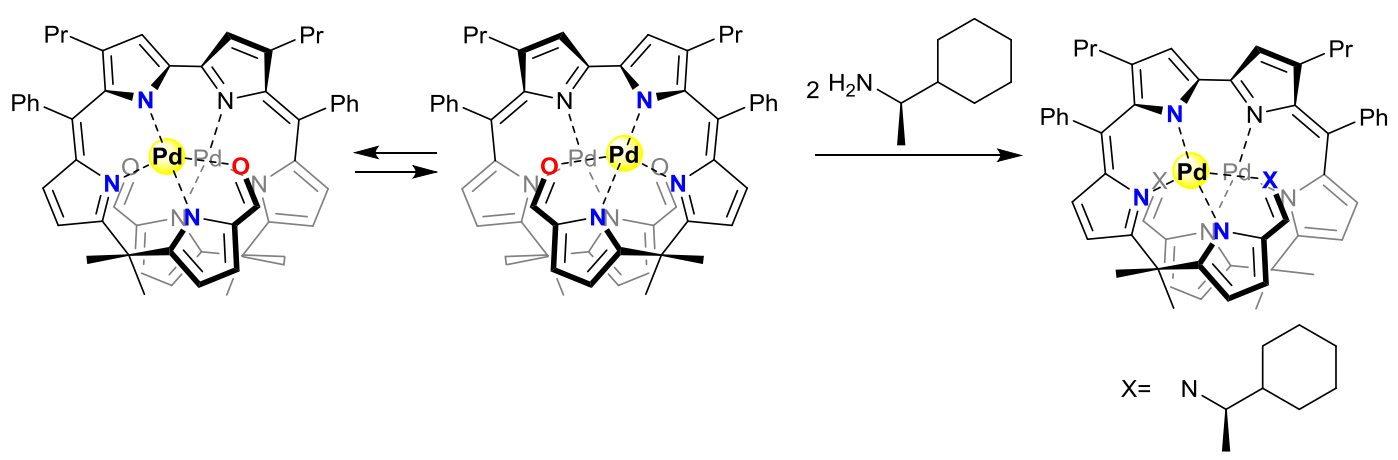

Such helical shapes can be produced by multinuclear complex systems containing oxime ligands and transition metal and lanthanide cations, exhibiting dynamic structural conversions. Akine and Nabeshima investigated a molecular leverage system [53]. They employed a ligand that contained two benzocrown rings attached to a chiral ethylenediamine unit as a transducer that formed a tetranuclear $\mathrm{Zn}(\mathrm{II})_{3}-\mathrm{La}(\mathrm{III})$ complex (Figure 7). Complexation of a shorter diammonium guest $\mathrm{H}_{3} \mathrm{~N}^{+}-\left(\mathrm{CH}_{2}\right)_{n}-\mathrm{NH}_{3}{ }^{+}$ ( $n=4,5$, or 6$)$ with the two crown rings produced a $P$-helical structure, while the longer guest $\mathrm{H}_{3} \mathrm{~N}^{+}-\left(\mathrm{CH}_{2}\right)_{12}-\mathrm{NH}_{3}{ }^{+}$induced an $M$-helical structure.

Figure 7. Guest-induced helicity inversion of a tetranuclear metal complex.
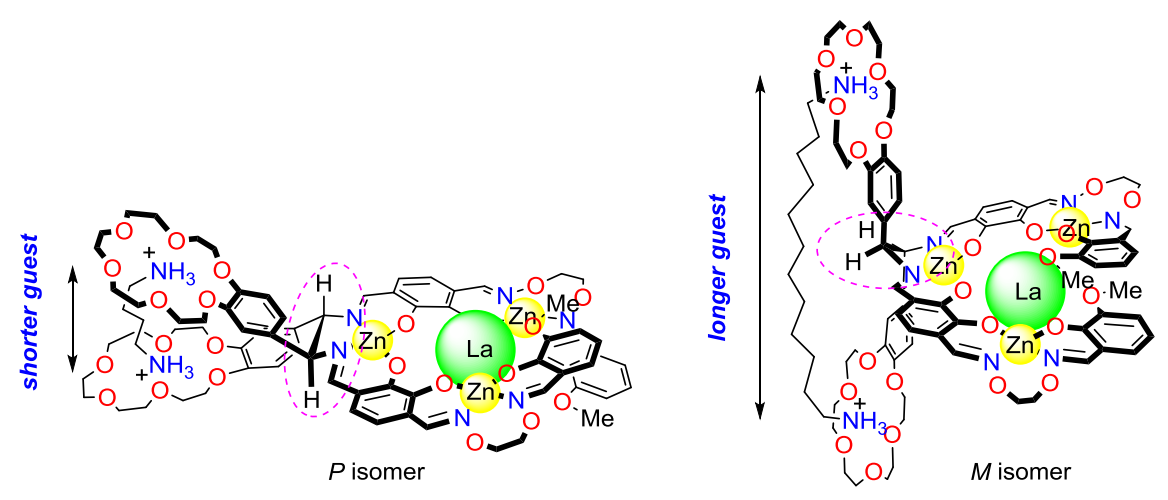

Stepwise helicity inversion of helical multinuclear complex also was accomplished by multisequential metal exchange (Figure 8) [54]. The chiral hexaoxime ligand favored a right-handed helical structure in the presence of three equivalents of $\mathrm{Zn}$ (II) cations, which could be inverted to a left-handed structure by addition of two more equivalents of $\mathrm{Zn}(\mathrm{II})$ cation $(P \rightarrow M)$. The helical direction was further inverted 
in a stepwise manner to the right-handed $(M \rightarrow P)$ and the left-handed structures $(P \rightarrow M)$ by subsequent addition of $\mathrm{Ba}(\mathrm{II})$ cation and $\mathrm{La}(\mathrm{III})$ cation (74:26 for the left- and right-handed diastereomers).

Figure 8. Stepwise multisequential helicity inversions of a hexaoxime-metal helicate.

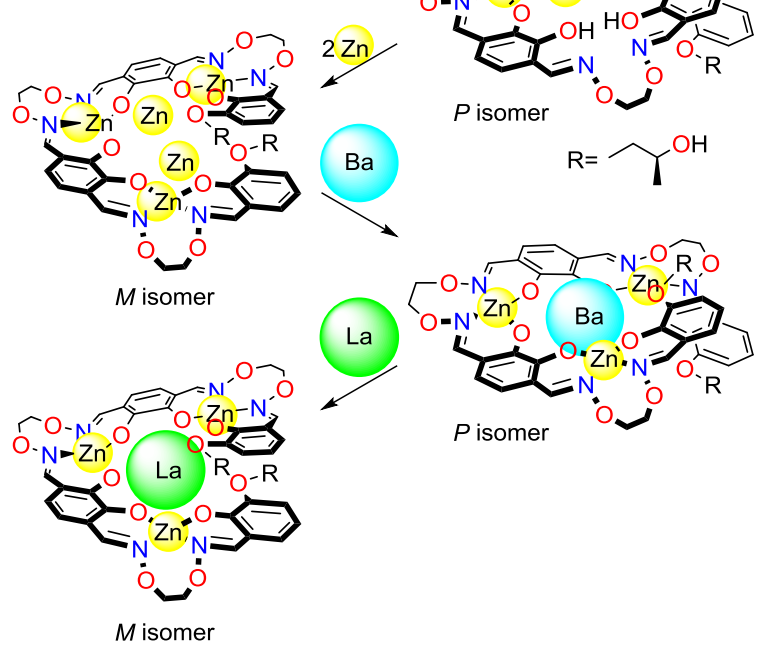

\section{Dynamic Production and Inversion of Supramolecular Chirality in Octahedral Metal Complexes}

Chirality in octahedral systems is interesting because many metal cations favor octahedral geometry and can provide more complex, dynamic, and functional systems including triple helicates [55,56], circular helicates [57,58], tetrahedral clusters [59], and heteronuclear helicates consisting of lanthanide and transition metal cations [60-62]. Chirality induction in octahedral metal complexes has been widely investigated using chiral ligands, starting with Werner's pioneering works [29,30], in which most metal centers were kinetically inert; their complexations often required long periods of time for completion, and purification procedures were required for obtaining diastereo- and enantiopure complexes. The dynamic supramolecular chirality systems discussed here include labile metal centers that allow dynamic ligand exchange and shape conversions.

Recently, Scott et al. successfully induced optically pure metal complexes with a tris(diimine) ligand prepared from a suitable amine and aldehyde in situ [63,64]. The chiral phenylethylamine and 2-pyridinecarboxaldehyde were added to a solution of $\mathrm{Fe}$ (II) cation, forming one optical isomer with an octahedral geometry (Figure 9). Combination of three sets of intramolecular $\pi-\pi$ interactions between the pyridine and phenyl rings in addition to steric interactions caused by three-point chiralities in the chiral ligands provided high stereoselective formation. Since the Fe(II) complex prepared with 2-pyridinecarboxaldehyde and chiral 2-butylamine produced four diastereomers [65], these weak $\pi-\pi$ interactions played an important role in stereoselective complex formation. This synthetic method was used to prepare optically pure dinuclear triple helicate (Figure 10), which maintained its stereochemistry in water. Even at $\mathrm{pH}=1.5$, it decomposed only $\sim 8 \%$ over 10 days. The triple helicate exhibited specific interaction with DNA and showed antimicrobial activity; the $\Lambda$ enantiomer had greater binding affinity with DNA, produced greater stabilization of the DNA duplex, and exhibited 
greater antimicrobial activity than the corresponding $\Delta$ enantiomer [66]. The corresponding triple helicate exhibited high, stereodependent toxicity to human colon cancer cell lines, but no significant toxicity to Gram-positive and Gram-negative bacteria [67]. The dinuclear helicates also exhibited enantioselective inhibition of amyloid- $\beta$ aggregation [68]. Thus, these dinuclear helicates are strong candidates for new enantioselective pharmaceuticals.

Figure 9. Diastereoselective complexation between a labile $\mathrm{Fe}(\mathrm{II})$ center and chiral tris(imine) ligand.

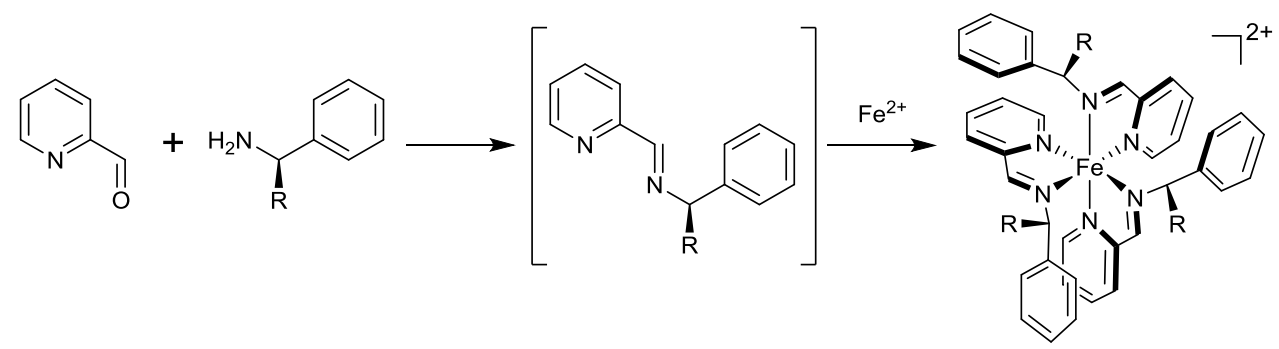

Figure 10. Stereoselective formation of a dinuclear Fe(II) complex with a chiral tris(diimine) ligand.

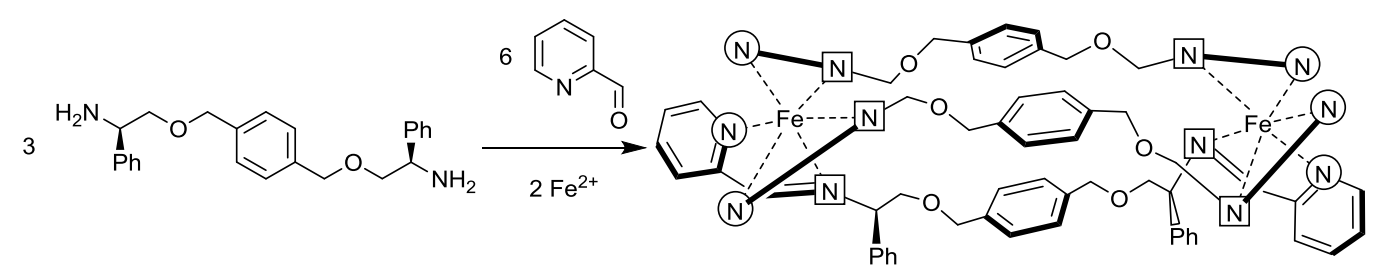

Nitschke et al. developed a tetrahedral chiral metal cage prepared using 6 eqs. of 6,6'-diformyl-3,3'bipyridine and 12 eqs. chiral amine in the presence of 4 eqs. Fe(II) cation [69,70]. Each metal center in the chiral cage had octahedral geometry with the same stereogenic configuration: $(S)$-1-phenylethylaminegenerated $\Delta$ configuration at all metal centers. Interestingly, addition of the chiral amine (S)-1-phenylethylamine to the solution containing the racemic cage with the achiral amine subcomponent $p$-toluidine promoted induction of the $\Delta \Delta \Delta \Delta$ chiral cage (Figure 11). The CD intensities of the racemic cage obtained by the addition of 6 eqs. of $(S)$-1-phenylethylamine were similar to those of the $\Delta \Delta \Delta \Delta$ cage, and the CD intensities increased nonlinearly with the \%ee of 1-phenylethylamine, indicating cooperative communication between metal centers.

They also found that tetranuclear Fe(II) cage complexes containing chiral 2-butylamine were formed with high stereoselectivity $(63 \% \sim 89 \%$ de) [65]. The low stereoselectivity ( $c a .0 .5 \%$ ee) of the corresponding mononuclear Fe(II) complex indicated stereochemical communication between the Fe(II) centers in the tetranuclear cage. The tetranuclear Fe(II) cage prepared from tris(formylpyridyl)benzene and (S)-1-cyclohexylethylamine also was obtained as a $\Delta \Delta \Delta \Delta$ chiral isomer. When the chiral amine subcomponent was displaced by the achiral amine tris(2-aminoethyl)amine, the cage retained its stereochemistry with high enantiomer excess (99\%ee) (Figure 12) [71]. 
Figure 11. Chiral cage formation from racemic cage by subcomponent substitution.

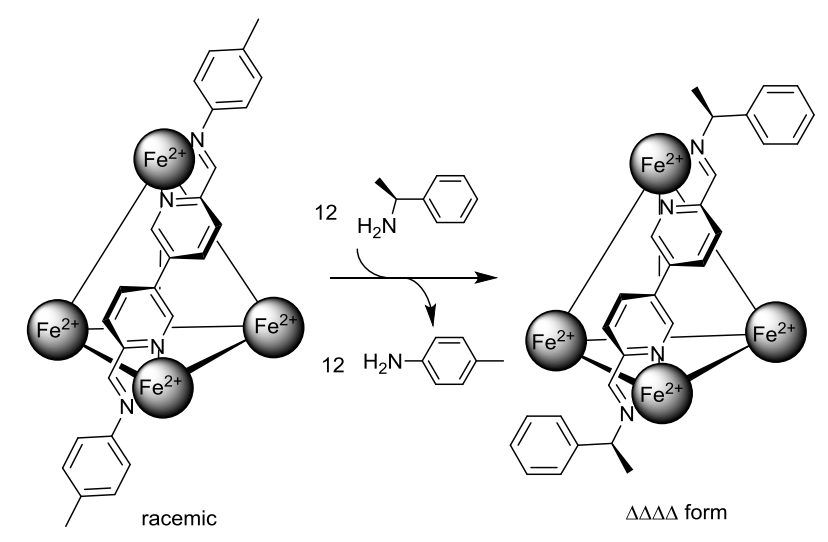

Figure 12. Chiral cage formation and chirality memory.

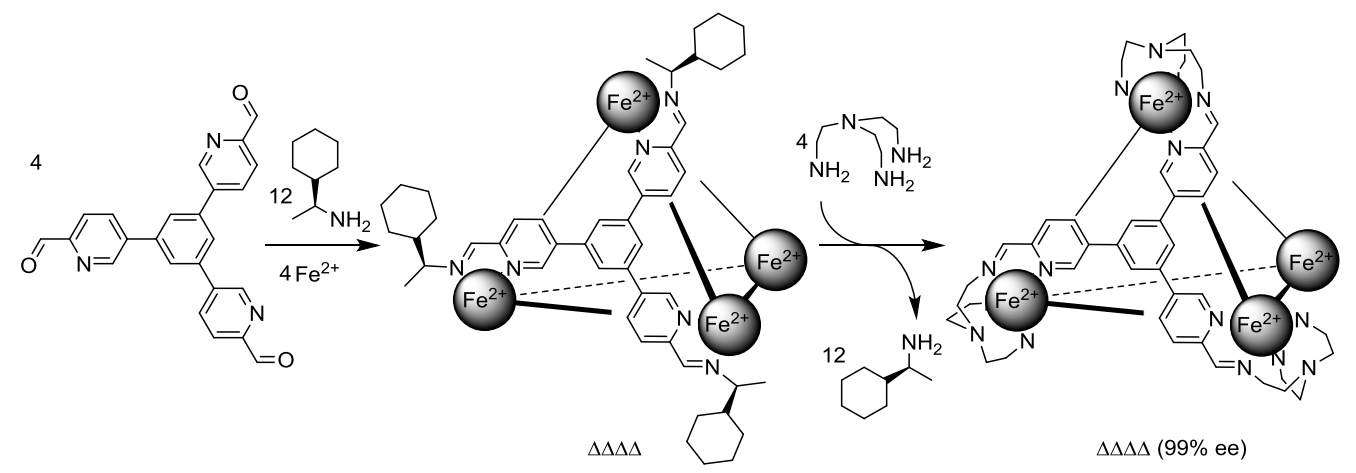

Raymond et al. reported the diastereoselective formation of a tetrahedral cage assembled using six biscatecholates with chiral amide terminals and four $\mathrm{Ga}$ (III) cations without involving any cationic species [72]. The chiral cage possessed greater stability toward air oxidation and low $\mathrm{pH}$ compared to the corresponding tetrahedral cage without chiral amide terminals. The chiral cage functioned as an efficient catalyst for enantioselective and chemoselective carbonyl-ene cyclization of a neutral substrate (Figure 13).

Figure 13. Enantioselective and chemoselective cyclization of a neutral substrate catalyzed by the $\Delta \Delta \Delta \Delta$ tetrahedral cage.

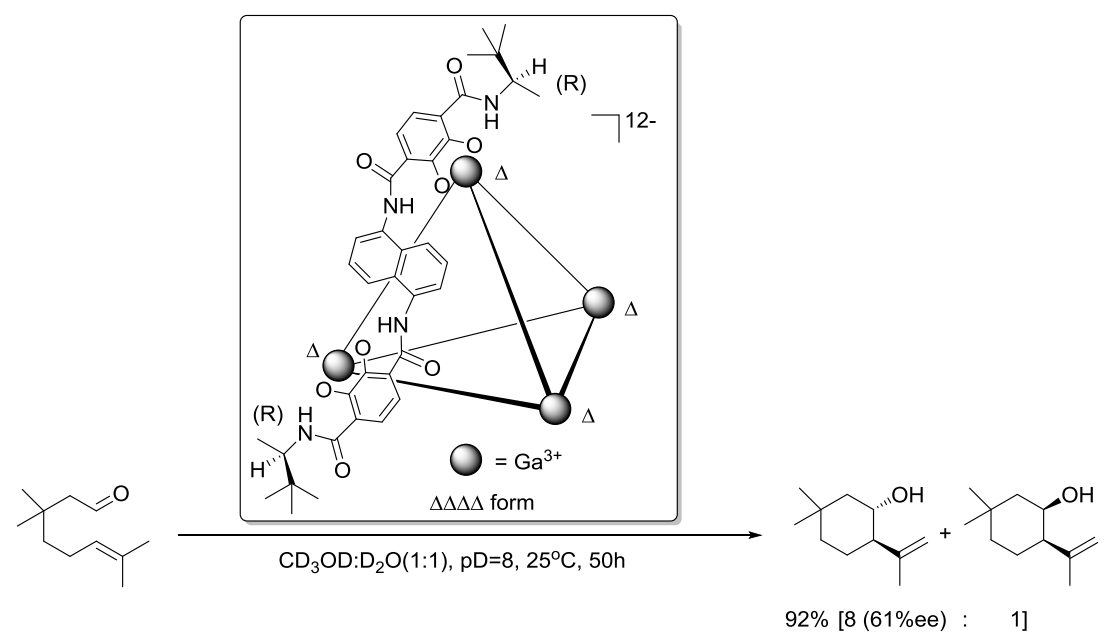


Yashima et al. designed a chirality transfer system of an octahedral tris-bipyridyl Fe(II) complex having helical oligopeptides at the 5 and 5 ' positions of 2,2'-bipyridine (Figure 14) [73]. Introduction of $(S)$-valine in the oligopeptide induced a right-handed helical structure in the peptide chain, which information further relayed to the octahedral Fe(II) center to induce the $\Delta$ structure (de $=85 \%$ which increased to $98 \%$ in the presence of $\mathrm{Cl}^{-}$anion). When a racemic $\mathrm{Co}$ (II) complex produced with achiral peptide ligands was mixed with a chiral $\Lambda \mathrm{Co}$ (II) analog of the $\mathrm{Fe}(\mathrm{II})$ complex, chirality amplification around $\mathrm{Co}$ (II) center and in achiral peptide helices were observed via chirality transfer from chiral peptide chains to metal center and to achiral peptide chains.

Figure 14. Chirality induction in an octahedral tris-bipyridyl Fe(II) complex induced by $(S)$-valine via a helical tetrapeptides.

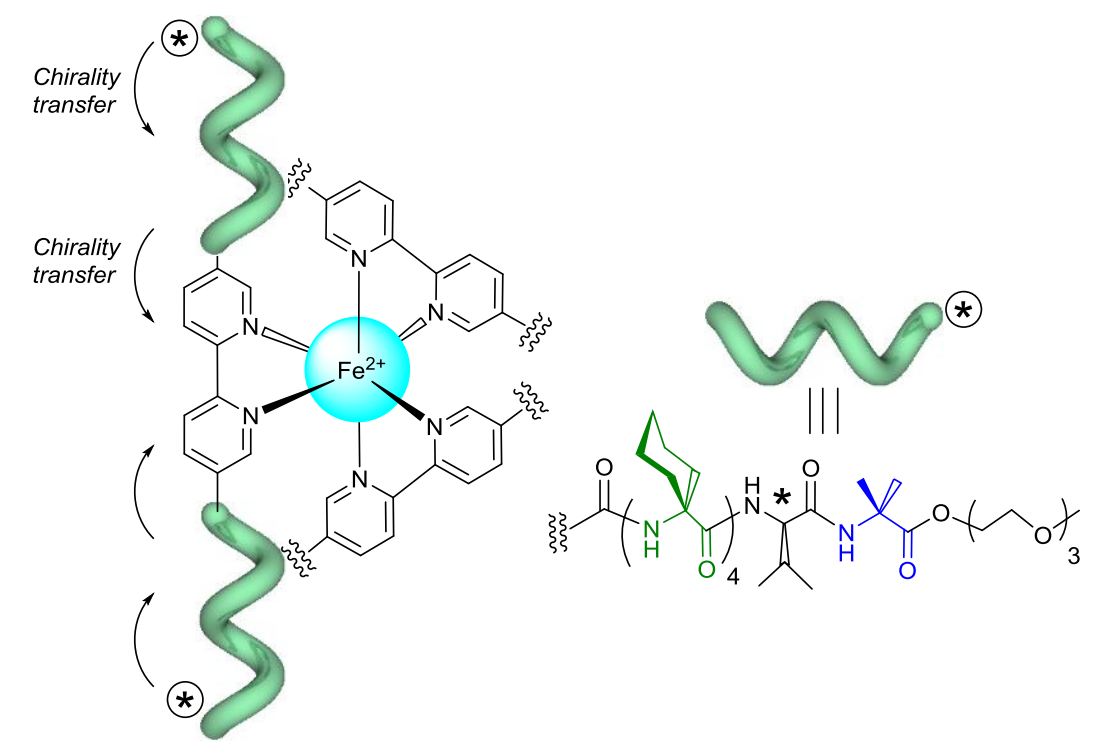

Miyake et al. demonstrated that the labile Co(II) complex with a chiral tetradentate ligand containing amide linkages acted as a helicity inversion unit in response to achiral $\mathrm{NO}_{3}{ }^{-}$anion (Figure 15) $[74,75]$. In a solid complex prepared by mixing the chiral ligand and $\mathrm{Co}\left(\mathrm{ClO}_{4}\right)_{2} \cdot 6 \mathrm{H}_{2} \mathrm{O}$, the Co(II) complex formed the $\Lambda$ cis- $\alpha$ structure, in which both coordinating nitrogen atoms adopted the $(S)$ configuration. The ${ }^{1} \mathrm{H}$ NMR spectrum showed only one paramagnetic complex, indicating that the asymmetric helical structure was retained in solution. This complex exhibited a positive $\mathrm{CD}$ signal in the range of a d-d transition in $\mathrm{CH}_{3} \mathrm{CN} / \mathrm{CH}_{2} \mathrm{Cl}_{2}$ (1/9) solution. However, the addition of 10 eqs. of $\mathrm{NO}_{3}{ }^{-}$anion dynamically changed its sign to negative, indicating helicity inversion around the $\mathrm{Co}$ (II) center from the $\Lambda$ to the $\Delta$ form. The $\Lambda / \Delta$ ratio of the $\mathrm{Co}$ (II) complex in $\mathrm{CD}_{3} \mathrm{CN} / \mathrm{CD}_{2} \mathrm{Cl}_{2}$ (1/9) at room temperature was $15 / 85$ as determined by ${ }^{1} \mathrm{H}$ NMR. Crystal structure analysis of the complex of the related ligand and $\mathrm{Co}\left(\mathrm{NO}_{3}\right)_{2} \cdot 6 \mathrm{H}_{2} \mathrm{O}$ revealed that one $\mathrm{NO}_{3}{ }^{-}$anion coordinated with the $\mathrm{Co}(\mathrm{II})$ center in a bidentate fashion while the other $\mathrm{NO}_{3}{ }^{-}$anion formed hydrogen bonds with the amide hydrogen. Thus, the cooperative action of the two $\mathrm{NO}_{3}{ }^{-}$anions stabilized the $\Delta$ form more effectively than the corresponding $\Lambda$ form. The $\Lambda / \Delta$ ratio of the ligand $-\mathrm{Co}\left(\mathrm{NO}_{3}\right)_{2} \cdot 6 \mathrm{H}_{2} \mathrm{O}$ complex also could be adjusted by changing the solvent components: $\Lambda / \Delta=88 / 12$ in $\mathrm{CH}_{3} \mathrm{CN}$ and $31 / 69$ in $\mathrm{CH}_{3} \mathrm{CN} / \mathrm{CH}_{2} \mathrm{Cl}_{2}$ (1/9). In methanol or aqueous solution, the $\mathrm{CD}$ and ${ }^{1} \mathrm{H}$ NMR spectra of the complex showed the existence of 
only the $\Lambda$ complex, indicating $\mathrm{NO}_{3}{ }^{-}$anion did not interact adequately with the $\mathrm{Co}$ (II) center or the amide hydrogens for inversion of its helical direction due to the higher donor number of these solvents.

Figure 15. $\mathrm{NO}_{3}{ }^{-}$anion-induced helicity inversion of a $\mathrm{Co}(\mathrm{II})$ complex.
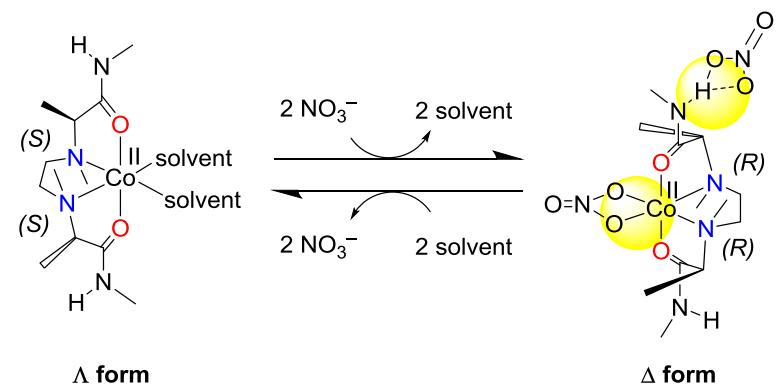

This helicity switching system was applied successfully to the inversion of peptide helices. The racemic peptide, $-(\mathrm{Aib}-\Delta \mathrm{Phe})_{2}-\mathrm{Aib}-\mathrm{OCH}_{3}(\mathrm{Aib}=\alpha$-aminoisobutyric acid, $\Delta \mathrm{Phe}=\alpha, \beta$-didehydrophenylalanine) was attached to both ends of a chiral $N, N^{\prime}$-ethylene-bis[N-methyl-( $S$ )-alanine] ligand (Figure 16) [76]. The peptide ligand obtained, which possessed 310 intramolecular hydrogen bonding, complexed with $\mathrm{Zn}\left(\mathrm{ClO}_{4}\right)_{2}, \mathrm{Co}\left(\mathrm{ClO}_{4}\right)_{2}$, or $\mathrm{Ni}\left(\mathrm{ClO}_{4}\right)_{2}$ to form a left-handed $\Lambda$ cis- $\alpha$ structure around the metal center and a right-handed $P$ helical structure in the peptide chains containing two 310 intramolecular hydrogen bonds in each peptide chain. The addition of $\mathrm{NO}_{3}{ }^{-}$anion inversed helicity around the metal center $(\Lambda \rightarrow \Delta)$, as well as the directions of both peptide helices $(P \rightarrow M)$. Thus, achiral $\mathrm{NO}_{3}{ }^{-}$anion has a unique ability to change the helical natures of peptides in cooperation with a chiral metal unit.

Figure 16. Helicity inversion around a metal center and sequential chirality transfer to peptide helices (left) and $\mathrm{CD}$ spectral changes upon addition of $\mathrm{NO}_{3}{ }^{-}$anion (right). Reproduced by permission of American Chemical Society [73].
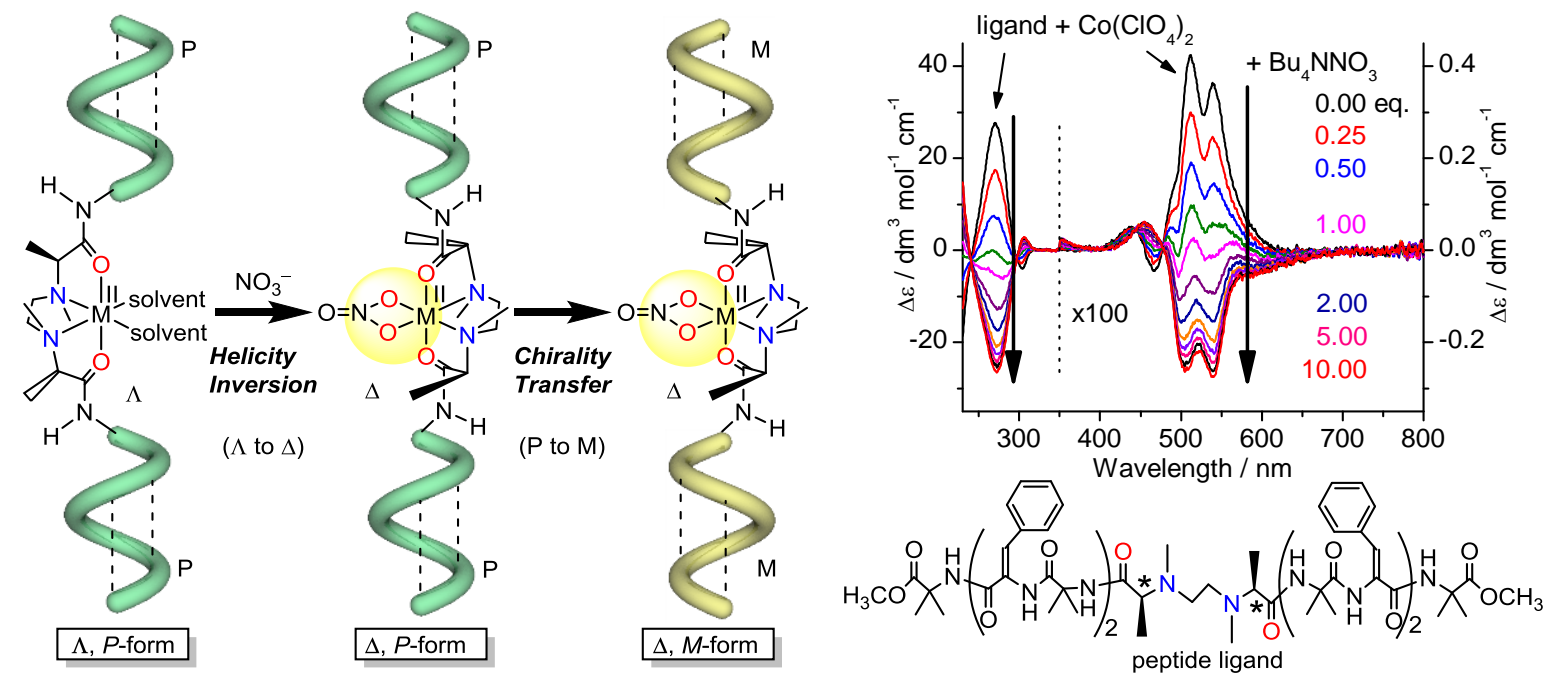

A chiral bisalanine ligand with 2,5-dimethoxyaniline amide terminals also formed a left-handed $\Lambda$ cis- $\alpha$ structure by the complexation with $\mathrm{Co}\left(\mathrm{ClO}_{4}\right)_{2}$ or $\mathrm{Co}(\mathrm{OTf})_{2}$, which exhibited acid-base-triggered elastic molecular motion, as well as helicity inversion of the metal center $(\Lambda \rightleftarrows \Delta)$ (Figure 17) [77]. When a strong organic base, such as $N, N, N^{\prime}, N^{\prime}$-tetramethyl-1,8-naphthalenediamine, deprotonated the 
secondary amide groups, the linkage isomerism at the amide coordination sites promoted conversion to the contracted complex. Successive addition of trifluoromethanesulfonic acid protonated the amide groups and restored the shape to its original extended form. This acid-base-triggered contraction/extension molecular motion was fully reversible. The contracted complex also could be converted to the extended $\Delta$-form with an opposite helical structure by adding an acid in the presence of the $\mathrm{NO}_{3}{ }^{-}$anion. Thus, combining two external stimuli promotes two different molecular motions.

Figure 17. Stretching and inverting motions of a $\mathrm{Co}(\mathrm{II})$ complex.

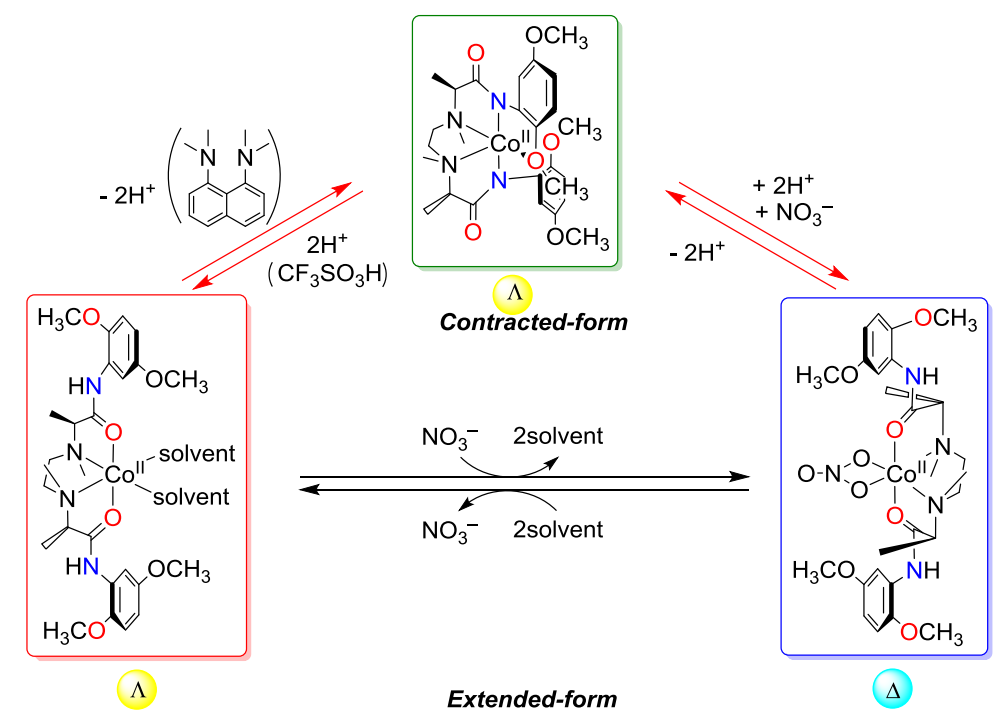

\section{Conclusions}

This review highlights the recent progress of supramolecular chiral complexes with dynamic coordination chemistry for the development of structurally and functionally defined metal complexes. Since the metal complexes have characteristic features including redox reactivity, unique spectroscopic and magnetic properties, and coordination geometry and dynamic coordination bonding, they are promising candidates for supramolecular chirality switching, which offers advantages compared to organic chiral foldamers constructed only from stable covalent bonds. Recent developments have advanced the field of supramolecular chirality on coordination chemistry. Using specific interactions between side chains within molecules and external stimuli, several labile metal helicates were stereospecifically induced to produce enantioselective pharmaceuticals and enantioselective catalysts. In addition, helical structures could be dynamically converted as observed in biological DNA and proteins. Thus, labile metal helicates are useful for designing sophisticated supramolecular chirality materials. The design and implementation of chirality recognition and regulation of dynamic ordering advances the emerging field of molecular-based nanoscience for development of substances with integrated functions. Metal coordination chemistry provides effective supramolecular chirality devices that can be applied to material science and nanotechnology. 


\section{Acknowledgments}

The author is grateful to Japan Society for the Promotion of Science (Grant-in-Aids for Scientific Research 26102540).

\section{Conflicts of Interest}

The author declares no conflict of interest.

\section{References}

1. Voet, D.; Voet, J.G. Biochemistry, 4th ed.; John Wiley \& Sons, Inc.: Hoboken, NJ, USA, 2011.

2. Buschmann, H.; Hauptmann, M.; Niessing, D.; Lloyd, C.W.; Schäffnera, A.R. Helical growth of the Arabidopsis mutant tortifolia2 does not depend on cell division patterns but involves handed twisting of isolated cells. Plant Cell 2009, 21, 2090-2106.

3. Capdevila, J.; Vogan, K.J.; Tabin, C.J.; Belmonte, J.C.I. Mechanisms of left-right determination in vertebrates. Cell 2000, 101, 9-21.

4. Hashimoto, T. Molecular genetic analysis of left-right handedness in plants. Philos. Trans. R. Soc. Lond. B 2002, 357, 799-808.

5. Samatey, F.A.; Imada, K.; Nagashima, S.; Vonderviszt, F.; Kumasaka, T.; Yamamoto, M.; Namba, K. Structure of the bacterial flagellar protofilament and implications for a switch for supercoiling. Nature 2001, 410, 331-337.

6. Song, G.; Ren, J. Recognition and regulation of unique nucleic acid structures by small molecules. Chem. Commun. 2010, 46, 7283-7294.

7. Wang, G.; Christensen, L.A.; Vasquez, K.M. Z-DNA-forming sequences generate large-scale deletions in mammalian cells. Proc. Natl. Acad. Sci. USA 2006, 103, 2677-2682.

8. Abe, A.; Hiraga, K.; Imada, Y.; Hiejima, T.; Furuya, H. Screw-sense inversion characteristic of $\alpha$-helical poly( $\beta$-p-chlorobenzyl L-aspartate) and comparison with other related polyaspartates. Biopolymers 2005, 80, 249-257.

9. Pandey, A.K.; Thomas, K.M.; Forbes, C.R.; Zondlo, N.J. Tunable control of polyproline helix (PPII) structure via aromatic electronic effects: An electronic switch of polyproline helix. Biochemistry 2014, 53, 5307-5314.

10. Horng, J.-C.; Raines, R.T. Stereoelectronic effects on polyproline conformation. Protein Sci. 2006, $15,74-83$.

11. Schmid, F.X. Prolyl isomerases. Adv. Protein Chem. 2002, 59, 243-281.

12. Pastorino, L.; Sun, A.; Lu, P.-J.; Zhou, X.Z.; Balastik, M.; Finn, G.; Wulf, G.; Lim, J.; Li, S.-H.; $\mathrm{Li}, \mathrm{X}$; et al. The prolyl isomerase Pin1 regulates amyloid precursor protein processing and amyloid- $\beta$ production. Nature 2006, 440, 528-534.

13. Suk, J.-M.; Naidu, V.R.; Liu, X.; Lah, M.S.; Jeong, K.-S. A foldamer-based chiroptical molecular switch that displays complete inversion of the helical sense upon anion binding. J. Am. Chem. Soc. 2011, 133, 13938-13941.

14. Jiang, X.; Lim, Y.-K.; Zhang, B.J.; Opsitnick, E.A.; Baik, M.-H.; Lee, D. Dendritic molecular switch: Chiral folding and helicity inversion. J. Am. Chem. Soc. 2008, 130, 16812-16822. 
15. Opsitnick, E.A.; Jiang, X.; Hollenbeck, A.N.; Lee, D. Hydrogen-bond-assisted helical folding of propeller-shaped molecules: Effects of extended $\pi$-conjugation on chiral selection, conformational stability, and exciton coupling. Eur. J. Org. Chem. 2012, 708-720.

16. Lu, W.; Du, G.; Liu, K.; Jiang, L.; Ling, J.; Shen, Z. Chiroptical inversion induced by rotation of a carbon-carbon single bond: An experimental and theoretical study. J. Phys. Chem. A 2014, 118, 283-292.

17. Kang, J.; Miyajima, D.; Itoh, Y.; Mori, T.; Tanaka, H.; Yamauchi, M.; Inoue, Y.; Harada, S.; Aida, T. $\mathrm{C}_{5}$-Symmetric chiral corannulenes: Desymmetrization of bowl inversion equilibrium via "intramolecular" hydrogen-bonding network. J. Am. Chem. Soc. 2014, 136, 10640-10644.

18. Kolomiets, E.; Berl, V.; Lehn, J.-M. Chirality induction and protonation-induced molecular motions in helical molecular strands. Chem. Eur. J. 2007, 13, 5466-5479.

19. Hua, Y.; Flood, A.H. Flipping the switch on chloride concentrations with a light-active foldamer. J. Am. Chem. Soc. 2010, 132, 12838-12840.

20. Yashima, E.; Maeda, K.; Iida, H.; Furusho, Y.; Nagai, K. Helical polymers: Synthesis, structures, and functions. Chem. Rev. 2009, 109, 6102-6211.

21. Shimomura, K.; Ikai, T.; Kanoh, S.; Yashima, E.; Maeda, K. Switchable enantioseparation based on macromolecular memory of a helical polyacetylene in the solid state. Nat. Chem. 2014, 6, 429-434.

22. Brown, R.A.; Diemer, V.; Webb, S.J.; Clayden, J. End-to-end conformational communication through a synthetic purinergic receptor by ligand-induced helicity switching. Nat. Chem. 2013, 5, 853-860.

23. Fujiki, M. Switching handedness in optically active polysilanes. J. Organomet. Chem. 2003, 685, $15-34$.

24. Zhang, S.; Zhou, J.; Park, Y.-S.; Rho, J.; Singh, R.; Nam, S.; Azad, A.K.; Chen, H.-T.; Yin, X.; Taylor, A.J.; et al. Photoinduced handedness switching in terahertz chiral metamolecules. Nat. Commun. 2012, 3, doi:10.1038/ncomms1908.

25. Manchineella, S.; Prathyusha, V.; Priyakumar, U.D.; Govindaraju, T. Solvent-induced helical assembly and reversible chiroptical switching of chiral cyclic-dipeptide-functionalized naphthalenediimides. Chem. Eur. J. 2013, 19, 16615-16624.

26. Sargsyan, G.; Schatz, A.A.; Kubelka, J.; Balaz, M. Formation and helicity control of ssDNA templated porphyrin nanoassemblies. Chem. Commun. 2013, 49, 1020-1022.

27. Pijper, D.; Jongejan, M.G.M.; Meetsma, A.; Feringa, B.L. Light-controlled supramolecular helicity of a liquid crystalline phase using a helical polymer functionalized with a single chiroptical molecular switch. J. Am. Chem. Soc. 2008, 130, 4541-4552.

28. San Jose, B.A.; Yan, J.; Akagi, K. Dynamic switching of the circularly polarized luminescence of disubstituted polyacetylene by selective transmission through a thermotropic chiral nematic liquid crystal. Angew. Chem. Int. Ed. 2014, 126, 10817-10820.

29. Borovkov, V. Supramolecular chirality in porphyrin chemistry. Symmetry 2014, 6, 256-294.

30. Tsukube, H.; Shinoda, S. Lanthanide complexes in molecular recognition and chirality sensing of biological substrates. Chem. Rev. 2002, 102, 2389-2403.

31. Miyake, H.; Terada, K.; Tsukube, H. Lanthanide tris( $\beta$-diketonates) as useful probes for chirality determination of biological amino alcohols in vibrational circular dichroism: Ligand to ligand chirality transfer in lanthanide coordination sphere. Chirality 2014, 26, 293-299. 
32. Ernst, K.-H.; Wild, F.R.W.P.; Blacque, O.; Berke, H. Alfred Werner's coordination chemistry: New insights from old samples. Angew. Chem. Int. Ed. 2011, 50, 10780-10787.

33. Constable, E.C.; Housecroft, C.E. Coordination chemistry: The scientific legacy of Alfred Werner. Chem. Soc. Rev. 2013, 42, 1429-1439.

34. Crassous, J. Transfer of chirality from ligands to metal centers: Recent examples. Chem. Commun. 2012, 48, 9684-9692.

35. Miyake, H.; Tsukube, H. Coordination chemistry strategies for dynamic helicates: Time-programmable chirality switching with labile and inert metal helicates. Chem. Soc. Rev. 2012, 41, 6977-6991.

36. Durot, S.; Reviriego, F.; Sauvage, J.-P. Copper-complexed catenanes and rotaxanes in motion: 15 years of molecular machines. Dalton Trans. 2010, 39, 10557-10570.

37. Forgan, R.S.; Sauvage, J.-P.; Stoddart, J.F. Chemical topology: Complex molecular knots, links, and entanglements. Chem. Rev. 2011, 111, 5434-5464.

38. Helm, L.; Merbach, A.E. Inorganic and bioinorganic solvent exchange mechanisms. Chem. Rev. 2005, 105, 1923-1959.

39. Lehn, J.-M.; Rigault, A.; Siegel, J.; Harrowfield, J.; Chevrier, B.; Moras, D. Spontaneous assembly of double-stranded helicates from oligobipyridine ligands and copper(I) cations: Structure of an inorganic double helix. Proc. Natl. Acad. Sci. USA 1987, 84, 2565-2569.

40. Piguet, C.; Bernardinelli, G.; Hopfgartner, G. Helicates as versatile supramolecular complexes. Chem. Rev. 1997, 97, 2005-2062.

41. Albrecht, M. "Let's twist again" sdouble-stranded, triple-stranded, and circular helicates. Chem. Rev. 2001, 101, 3457-3497.

42. Howson, S.E.; Scott, P. Approaches to the synthesis of optically pure helicates. Dalton Trans. 2011, 40, 10268-10277.

43. Ito, H.; Ikeda, M.; Hasegawa, T.; Furusho, Y.; Yashima, E. Synthesis of complementary double-stranded helical oligomers through chiral and achiral amidinium-carboxylate salt bridges and chiral amplification in their double-helix formation. J. Am. Chem. Soc. 2011, 133, 3419-3432.

44. Furusho, Y.; Goto, H.; Itomi, K.; Katagiri, H.; Miyagawa, T.; Yashima, E. Synthesis and optical resolution of a $\mathrm{Cu}(\mathrm{I})$ double-stranded helicate with ketimine-bridged tris(bipyridine) ligands. Chem. Commun. 2011, 47, 9795-9797.

45. Boiocchi, M.; Brega, V.; Ciarrocchi, C.; Fabbrizzi, L.; Pallavicini, P. Dicopper double-strand helicates held together by additional $\pi-\pi$ interactions. Inorg. Chem. 2013, 52, 10643-10652.

46. Yamada, H.; Furusho, Y.; Yashima, E. Diastereoselective imine-bond formation through complementary double-helix formation. J. Am. Chem. Soc. 2012, 134, 7250-7253.

47. Kovaříček, P.; Lehn, J.-M. Merging constitutional and motional covalent dynamics in reversible imine formation and exchange processes. J. Am. Chem. Soc. 2012, 134, 9446-9455.

48. Stadler, A.-M.; Lehn, J.-M.P. Coupled nanomechanical motions: Metal-ion-effected, ph-modulated, simultaneous extension/contraction motions of double-domain helical/linear molecular strands. J. Am. Chem. Soc. 2014, 136, 3400-3409.

49. Tsujimoto, Y.; Kojima, T.; Hiraoka, S. Rate-determining step in the self-assembly process of supramolecular coordination capsules. Chem. Sci. 2014, 5, 4167-4172. 
50. Sato, S.; Ishido, Y.; Fujita, M. Remarkable stabilization of $\mathrm{M}_{12} \mathrm{~L}_{24}$ spherical frameworks through the cooperation of $48 \mathrm{Pd}(\mathrm{II})$-pyridine interactions. J. Am. Chem. Soc. 2009, 131, 6064-6065.

51. Miyake, H.; Ueda, M.; Murota, S.; Sugimoto, H.; Tsukube, H. Helicity inversion from left- to right-handed square planar Pd(II) complexes: Synthesis of a diastereomer pair from a single chiral ligand and their structure dynamism. Chem. Commun. 2012, 48, 3721-3723.

52. Eerdun, C.; Hisanaga, S.; Setsune, J. Single helicates of dipalladium(II) hexapyrroles: Helicity induction and redox tuning of chiroptical properties. Angew. Chem. Int. Ed. 2013, 52, 929-932.

53. Akine, S.; Hotate, S.; Nabeshima, T. A molecular leverage for helicity control and helix inversion. J. Am. Chem. Soc. 2011, 133, 13868-13871.

54. Akine, S.; Sairenji, S.; Taniguchi, T.; Nabeshima, T. Stepwise helicity inversions by multisequential metal exchange. J. Am. Chem. Soc. 2013, 135, 12948-12951.

55. Krämer, R.; Lehn, J.-M.; de Cian, A.; Fischer, J. Self-assembly, structure, and spontaneous resolution of a trinuclear triple helix from an oligobipyridine ligand and $\mathrm{Ni}^{\mathrm{iI}}$ ions. Angew. Chem. Int. Ed. 1993, 32, 703-706.

56. Lehn, J.-M. Toward self-organization and complex matter. Science 2002, 295, 2400-2403.

57. Hasenknopf, B.; Lehn, J.-M.; Kneisel, B.O.; Baum, G.; Fenske, D. Self-assembly of a circular double helicate. Angew. Chem. Int. Ed. 1996, 35, 1838-1840.

58. Hasenknopf, B.; Lehn, J.-M.; Boumediene, N.; Dupont-Gervais, A.; van Dorsselaer, A.; Kneisel, B.; Fenske, D. Self-assembly of tetra- and hexanuclear circular helicates. J. Am. Chem. Soc. 1997, 119, 10956-10962.

59. Wang, Z.J.; Clary, K.N.; Bergman, R.G.; Raymond, K.N.; Toste, F.D. A supramolecular approach to combining enzymatic and transition metal catalysis. Nat. Chem. 2013, 5, 100-103.

60. Aboshyan-Sorgho, L.; Cantuel, M.; Bernardinellib, G.; Piguet, C. Looking for the origin of the switch between coordination-captured helicates and catenates. Dalton Trans. 2012, 41, 7218-7226.

61. Imbert, D.; Cantuel, M.; Bünzli, J.-C.G.; Bernardinelli, G.; Piguet, C. Extending lifetimes of lanthanide-based NIR emitters $(\mathrm{Nd}, \mathrm{Yb})$ in the millisecond range through $\mathrm{Cr}(\mathrm{III})$ sensitization in discrete bimetallic edifices. J. Am. Chem. Soc. 2003, 125, 15698-15699.

62. Aboshyan-Sorgho, L.; Nozary, H.; Aebischer, A.; Bünzli, J.-C.G.; Morgantini, P.-Y.; Kittilstved, K.R.; Hauser, A.; Eliseeva, S.V.; Petoud, S.; Piguet, C.; et al. Optimizing millisecond time scale near-infrared emission in polynuclear chrome(III)-lanthanide(III) complexes. J. Am. Chem. Soc. 2012, 134, 12675-12684.

63. Howson, S.E.; Allan, L.E.N.; Chmel, N.P.; Clarkson, G.J.; van Gorkum, R.; Scott, P. Self-assembling optically pure $\mathrm{Fe}(\mathrm{A}-\mathrm{B})_{3}$ chelates. Chem. Commun. 2009, 1727-1729.

64. Howson, S.E.; Allan, L.E.N.; Chmel, N.P.; Clarkson, G.J.; Deeth, R.J.; Faulkner, A.D.; Simpson, D.H.; Scott, P. Origins of stereoselectivity in optically pure phenylethaniminopyridine tris-chelates $\mathrm{M}\left(\mathrm{NN}^{\prime}\right) 3^{n+}(\mathrm{M}=\mathrm{Mn}, \mathrm{Fe}, \mathrm{Co}, \mathrm{Ni}$ and $\mathrm{Zn})$. Dalton Trans. 2011, 40, 10416-10433.

65. Ousaka, N.; Grunder, S.; Castilla, A.M.; Whalley, A.C.; Stoddart, J.F.; Nitschke, J.R. Efficient long-range stereochemical communication and cooperative effects in self-assembled $\mathrm{Fe}_{4} \mathrm{~L}_{6}$ cages. J. Am. Chem. Soc. 2012, 134, 15528-15537.

66. Howson, S.E.; Bolhuis, A.; Brabec, V.; Clarkson, G.J.; Malina, J.; Rodger, A.; Scott, P. Optically pure, water-stable metallo-helical "flexicate" assemblies with antibiotic activity. Nat. Chem. 2012, 4, 31-36. 
67. Faulkner, A.D.; Kaner, R.A.; Abdallah, Q.M.A.; Clarkson, G.; Fox, D.J.; Gurnani, P.; Howson, S.E.; Phillips, R.M.; Roper, D.I.; Simpson, D.H.; et al. Asymmetric triplex metallohelices with high and selective activity against cancer cells. Nat. Chem. 2014, 6, 797-803.

68. Li, M.; Howson, S.E.; Dong, K.; Gao, N.; Ren, J.; Scott, P.; Qu, X. Chiral metallohelical complexes enantioselectively target amyloid $\beta$ for treating alzheimer's disease. J. Am. Chem. Soc. 2014, 136, 11655-11663.

69. Castilla, A.M.; Ramsay, W.J.; Nitschke, J.R. Stereochemistry in subcomponent self-assembly. Acc. Chem. Res. 2014, 47, 2063-2073.

70. Ousaka, N.; Clegg, J.K.; Nitschke, J.R. Nonlinear enhancement of chiroptical response through subcomponent substitution in M4L6 cages. Angew. Chem. Int. Ed. 2012, 51, 1464-1468.

71. Castilla, A.M.; Ousaka, N.; Bilbeisi, R.A.; Valeri, E.; Ronson, T.K.; Nitschke, J.R. High-fidelity stereochemical memory in a $\mathrm{Fe}^{\mathrm{II}}{ }_{4} \mathrm{~L}_{4}$ tetrahedral capsule. J. Am. Chem. Soc. 2013, 135, 17999-18006.

72. Zhao, C.; Sun, Q.-F.; Hart-Cooper, W.M.; DiPasquale, A.G.; Toste, F.D.; Bergman, R.G.; Raymond, K.N. Chiral amide directed assembly of a diastereo- and enantiopure supramolecular host and its application to enantioselective catalysis of neutral substrates. J. Am. Chem. Soc. 2013, 135, 18802-18805.

73. Ousaka, N.; Takeyama, Y.; Iida, H.; Yashima, E. Chiral information harvesting in dendritic metallopeptides. Nat. Chem. 2011, 3, 856-861.

74. Miyake, H.; Yoshida, K.; Sugimoto, H.; Tsukube, H. Dynamic helicity inversion by achiral anion stimulus in synthetic labile cobalt(II) complex. J. Am. Chem. Soc. 2004, 126, 6524-6525.

75. Miyake, H.; Sugimoto, H.; Tamiaki, H.; Tsukube, H. Dynamic helicity inversion in an octahedral cobalt(II) complex system via solvato-diastereomerism. Chem. Commun. 2005, 4291-4293.

76. Miyake, H.; Kamon, H.; Miyahara, I.; Sugimoto, H.; Tsukube, H. Time-programmed peptide helix inversion of a synthetic metal complex triggered by an achiral $\mathrm{NO}_{3}{ }^{-}$anion. J. Am. Chem. Soc. 2008, 130, 792-793.

77. Miyake, H.; Hikita, M.; Itazaki, M.; Nakazawa, H.; Sugimoto, H.; Tsukube, H. A chemical device that exhibits dual mode motions: Dynamic coupling of amide coordination isomerism and metal-centered helicity inversion in a chiral cobalt(II) complex. Chem. Eur. J. 2008, 14, 5393-5396.

(C) 2014 by the authors; licensee MDPI, Basel, Switzerland. This article is an open access article distributed under the terms and conditions of the Creative Commons Attribution license (http://creativecommons.org/licenses/by/4.0/). 